\title{
Sea Level across North Pacific's Wide Warm Surface Current
}

\author{
Kern E. Kenyon \\ 4632 North Lane, Del Mar, CA, USA \\ Correspondence to: Kern E. Kenyon, kernken@aol.com \\ Keywords: Sea Level, Geostrophy
}

Received: August 16, $2019 \quad$ Accepted: September 9, $2019 \quad$ Published: September 12, 2019

Copyright (c) 2019 by author(s) and Scientific Research Publishing Inc. This work is licensed under the Creative Commons Attribution International License (CC BY 4.0).

http://creativecommons.org/licenses/by/4.0/

\section{c) (i) Open Access}

\section{ABSTRACT}

Sea level across the wide warm northeastward current off California is calculated from hydrographic data along $35 \mathrm{~N}$ using the hydrostatic balance and the assumption that the warm mixed layer water floats on the colder stratified water underneath. It is found that the sea level is higher above the warm water by a maximum of $7 \mathrm{~cm}$ in the middle of the flow. However, the mean east/west slope of the sea surface is deduced to be too small to balance the Coriolis force on the northward current. Therefore, geostrophy, as it is usually understood, is not operating strictly within the surface layer itself.

\section{INTRODUCTION}

Off the coast of California, a wide $(4000 \mathrm{~km})$ warm surface current flows north [1]. Though shallow $(\leq 100 \mathrm{~m}$ thick) and slow $(10-20 \mathrm{~cm} / \mathrm{sec})$ nevertheless it is real and permanent based on available data, which include millions of individual ship-injection temperatures covering most of the North Pacific over a 30 -year period as well as a coast to coast hydrographic section from California to Japan along $35 \mathrm{~N}$.

What is not known at the present time is a complete understanding of the internal dynamics of this current. How are the physical forces kept in balance to allow such a large-scale flow to be permanently in a steady state? Where does geostrophy fit in to the picture?

Since it is important to eventually examine all aspects of the enormous physical phenomenon at hand, one characteristic in particular is selected for study below: the sea level elevation across the top of the warm water. Below the surface the warm water forms a lens, convex side down, a mixed layer with temperatures nearly uniform vertically. Sea level is estimated by using the published sea water density values [2] and the assumption that the warm mixed layer is floating on the colder water underneath. To my knowledge, this method has not been attempted before in any ocean.

Above the warm water lens it might be anticipated that there would exist a large-scale dome in the sea level height with the maximum height of the dome being located over the deepest mixed layer depths in the middle of the current. In general that is what is found below, and the greatest sea level height is computed to be $7 \mathrm{~cm}$. At the moment, there is apparently no way to compare this value with any outside inde- 
pendent information, but there is an internal consistency in the hydrographic data set as explained below.

\section{CALCULATION}

Consider that the lens of warm surface water is floating on the colder water underneath it and apply the hydrostatic balance in the vertical direction.

$$
\rho_{1} g h_{1}=\rho_{2} g h_{2}
$$

where $\rho_{1}$ is the density of the cold water at the base of the mixed layer with height $h_{1}$, and $\rho_{2}$ is the density of the nearly uniform water of the mixed layer of thickness $h_{2}$. Acceleration of gravity is $g$.

By definition sigma-t, $\sigma_{t}$, is [3]

$$
\sigma_{t}=(\rho-1) \times 10^{3}
$$

where the density, $\rho$, is given in units of grams per cubic centimeter. From (1) and (2) comes the difference in sea level, $\nabla h$, over the warm mixed layer

$$
\nabla h=h_{2}-h_{1} \approx h_{1}\left(\sigma_{t}^{1}-\sigma_{t}^{2}\right) \times 10^{-3}
$$

where $\sigma_{t}^{1}$ is related to $\rho_{1}$ and $\sigma_{t}^{2}$ to $\rho_{2}$. In (3) the approximation made is

$$
\left[10^{-3} \sigma_{t}^{2}\right]^{2} \ll 1
$$

To make Figure 1 the $\sigma_{t}$ values from 31 consecutive stations along $35 \mathrm{~N}$ at standard depths within the mixed layer were taken from the data report [2] and inserted into (3). Station spacing was constant at $91 \mathrm{~km}$ and east in on the right, west on the left in the figure. Standard depths in meters were: $0,10,20,30$, 50,75 and 100.

Station 45 is just outside the western edge of the warm current, and all the sea level height differences in Figure 1 are relative to that station. For example, the mixed layer depth at station 15 is $100 \mathrm{~m}$, then the seven $\sigma_{t}$ values at the standard depths of that station were averaged and subtracted from the averaged seven $\sigma_{t}$ value at station 45 , multiplied by $10^{-3}$ and $h_{1}=100 \mathrm{~m}$, and then converted into centimeters.

\section{DISCUSSION}

Sea level over the warm surface water is relatively high as Figure 1 shows and the shape of the curve is roughly that of a dome in cross-section with some indentations. One possible reason for the lack of smoothness of the curve is related to the standard depth intervals which are not constant but increase just in the region of the depth of the mixed layer. It is not any fault of the thermometers on the Niskin bottles attached to the cable that was lowered into the water column. Readings of temperature from these thermometers are very accurate. Since the Niskin bottles were never placed exactly at the standard depths, an interpolation scheme had to be used but this probably caused no problem either. However, the depth of the mixed layer, which is one of the factors in Equation (3), could have been missed by as much as $25 \mathrm{~m}$, or $1 / 4$ of a mixed layer depth of $100 \mathrm{~m}$.

On each station an STD instrument was used, giving an independent temperature trace continuously as a function of depth, but these data were also read only at the standard depths for publication in the data report [2]. Using the STD data a figure (not shown) was constructed very similar to Figure 1 with respect to the maximum value, the general shape of the curve and the indentations.

Figure 1 has some bearing on the balance of forces within the warm mixed layer. However, the mean slopes in sea level indicated are too small to balance the Coriolis force for a northward current any stronger than about $1 \mathrm{~cm} / \mathrm{sec}$. Though direct measurements are lacking, indirectly the observations have suggested that the northward flow of warm surface water is at least ten times bigger (i.e. around $10 \mathrm{~cm} / \mathrm{sec}$ or a bit more). Therefore, geostrophy, as normally thought of, is very likely not working inside the mixed layer.

Besides a sea level variation there is another way a geostrophic balance can take place, and that involves 


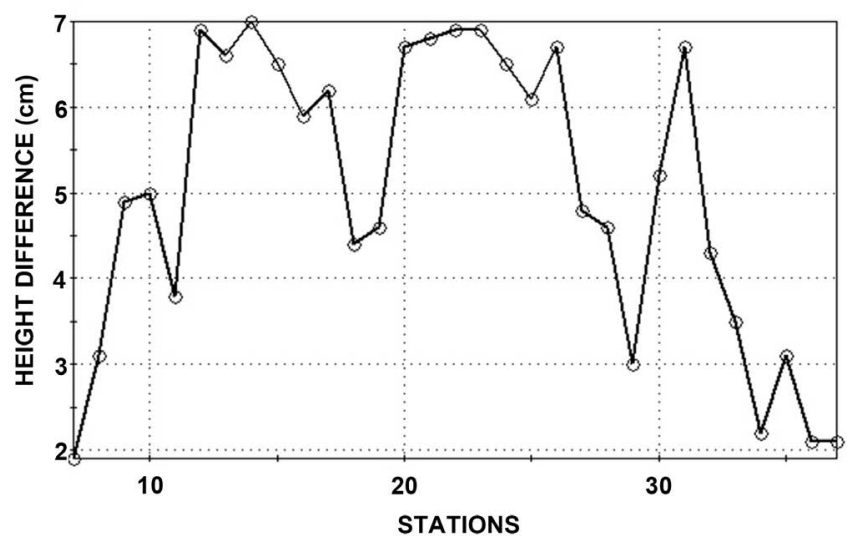

Figure 1. Sea level as a function of longitude along $35 \mathrm{~N}$ in the eastern Pacific. Station spacing is $91 \mathrm{~km}$.

a horizontal velocity shear in the current that has a magnitude exactly equal to the Coriolis parameter [4]. That a horizontal shear exists in the wide warm surface flow, especially in the western half, was proposed recently [5] in order to help explain the fact that the highest sea surface temperatures were significantly to the west of the region of deepest mixed layer depths in the middle. However, it is doubtful that a shear as large as the Coriolis parameter at $35 \mathrm{~N}$ could be present within the sluggish and wide northward flow in the mixed layer.

Consequently, in conclusion, there appears to be no horizontal balance of forces entirely inside the warm surface flow. Return flows of colder water to the south on either or both sides and below the northward flow must somehow be involved. For example, opposing Coriolis forces might largely cancel each other out. And for conservation of mass, return flows must exist.

If the above method were to be applied to the hydrographic section at $28 \mathrm{~S}$ in the South Pacific, similar results are expected. That is a possible project for the future.

\section{CONCLUSION}

The largest permanent surface current in the North Pacific is not in geostrophic balance in isolation. This prediction is based on computing the sea level height across the wide warm northward flow off California using closely spaced hydrographic data along $35 \mathrm{~N}$. Mean slopes of the sea level obtained are too small to balance the Coriolis force of the estimated north moving current inside the warm mixed layer at the surface. Other ways that the Coriolis force could be balanced are mentioned.

\section{CONFLICTS OF INTEREST}

The author declares no conflicts of interest regarding the publication of this paper.

\section{REFERENCES}

1. Kenyon, K.E. (1981) A Shallow Northeastward Current in the North Pacific. Journal of Geophysical Research, 86, 6529-6536. https://doi.org/10.1029/JC086iC07p06529

2. Data Report (1978) Indopac Expedition, Leg I. Univ. Calif., SIO Ref. 78-21.

3. Pickard, G.L. (1963) Descriptive Physical Oceanography. Pergamon Press, New York, 18.

4. Kenyon, K.E. (2019) Flow past a Sphere. Natural Science, 11, 95-97. https://doi.org/10.4236/ns.2019.113010

5. Kenyon, K.E. (2019) Shear in Pacific's Wide Warm Surface Currents. Natural Science, 11, 253-256. https://doi.org/10.4236/ns.2019.118025 